FESIEE

Fundación Emilio Soldevilla de la Ecostigacion y Desarrollo

\section{Management Letters / Cuadernos de Gestión}

\author{
journal homepage: http://www.ehu.eus/cuadernosdegestion/revista/es/
}

ISSN: 1131-6837 / e-ISSN: 1988-2157

\title{
Impact of Information Technology (IT) Governance on Business-IT Alignment
}

\section{Impacto del gobierno de las Tecnologías de Información (TI) en el alineamiento entre negocio y TI}

\author{
Weimar Santos Castellanos* \\ CENTRUM Catolica Graduate Business School - Pontificia Universidad Católica del Perú, Lima, Perú
}

* Corresponding author: Weimar Santos Castellanos. Centrum Católica Graduate Business School, Jr. Daniel Alomía Robles n. ${ }^{\circ} 125$, urbanización Los Álamos de Monterrico, Surco, Lima (Perú) - a20134372@pucp.pe - https://orcid.org/0000-0002-5304-5160

\section{A R T I C L E I N F O}

Received 16 July 2018, Accepted 16 April 2020

Available online 10 December 2020

DOI: $10.5295 / \mathrm{cdg} .180995 \mathrm{ws}$

JEL CODE: M150.

\begin{abstract}
A B S T R A C T
Purpose: This basic, quantitative, descriptive, cross-sectional research aims to empirically examine the impact of IT governance on business-IT alignment. Method: This study adopts the Structural Equation Model (SEM) technique with Confirmatory Factor Analysis (CFA) to evaluate the relationship between IT governance and business-IT alignment, testing three basic hypotheses on the data collected from 672 web-based surveys of companies in Colombia. Main finding: IT governance significantly and directly affects business-IT alignment, but there are no differences in such influence as per industry type or company size. Limitations: This study only considered companies located in Colombia with a limited sample size in several industry types, which may become a possibility for further studies. Additionally, the data collected relies on the honesty of respondents and is not completely free of bias.
\end{abstract}

Keywords: Information Technology, IT governance, IT governance practices, Business-IT alignment, IT strategic alignment, IT management.

\section{R E S U M E N}

Objetivo de la investigación: El propósito de esta investigación básica, cuantitativa, descriptiva y transversal es examinar empíricamente el impacto de la gobernanza de TI en el alineamiento de negocio y TI. Metodología: Este estudio adopta la técnica Modelo de Ecuaciones Estructurales (SEM) con Análisis Factorial Confirmatorio (CFA) con el fin de evaluar la relación planteada entre gobierno de TI y alineamiento de negocio y TI, poniendo a prueba tres hipótesis básicas, usando los datos recolectados procedentes de 672 encuestas realizadas vía web a empresas en Colombia. Hallazgos: Este estudio encontró que el gobierno de TI afecta de manera significativa y directa la alineación de negocio y de TI, pero no existen diferencias en dicha influencia entre tipos de industria y tamaños de empresa. Limitaciones: Este estudio solo tomó en cuenta empresas localizadas en Colombia con limitación en tamaño de muestra en varios sectores de actividad, lo que puede constituirse como una posibilidad para estudios posteriores. Adicionalmente, los datos recolectados están basados en la honestidad de los encuestados y no están completamente libres de sesgo.

Palabras clave: Tecnología de Información, Gobierno de TI, Prácticas de Gobierno TI, Alineamiento de negocio y TI, Alineamiento estratégico de TI, Gestión de TI. 


\section{INTRODUCTION}

Information technologies (IT) are one of the key factors in organizational competitiveness (Weill et al. 2002), along with processes, investments, expenses, IT assets (hardware, software and communications networks), and the firms' knowledge to provide technological services (Aduloju 2014; Mardikyan 2010). This is why organizations increasingly depend on IT and their capabilities to efficiently integrate IT resources into other organizational and management processes (Zhang et al. 2016). As a result, the IT management approach in many organizations has evolved from an operational support role to a more strategic role involving aspects such as business transformation, innovation, and obtaining IT-based business opportunities (Tanriverdi et al. 2010).

Since an organization's strategic IT management is increasingly based on its IT governance (ITG) (Caluwe and De Haes 2019; Cervone 2017; Kude et al. 2018), it is necessary to achieve adequate business and IT alignment (BITA) given its positive effects on business performance (Gerow et al. 2014; Wagner et al. 2014; Yayla and Hu 2012). Organizations will operate better when key IT resources are aligned with the business strategy and when appropriate structures are used to monitor the deployment and effective management of these resources (Coltman et al. 2015).

Despite the abundant body of knowledge of ITG and BITA, there is a need for describing and explaining the nature and scope of the relationships between ITG and strategic BITA, as well additional empirical evidence that allows for an integrated understanding of such relationship (De Haes and Van Grembergen 2009; Raymond et al. 2019). This leads to the following research questions: What is the impact of ITG practices on BITA? And consequently, will there be any differences in that impact depending on industry type or company size?

In response to the above questions, the research objectives are formulated: a) to study the direct effect of ITG on BITA, and b) to examine the moderating effects of industry type and company size on the relationship between ITG and BITA. To achieve these two objectives, an empirical research model was developed and tested using a Structural Equation Model (SEM), using survey data from a sample of 672 Colombian companies. It was found that ITG has a positive effect on BITA and there are no differences in the relationship according to industry type and company size.

The rest of the article is divided as follows: Section 2 presents the literature review and the following section shows the theoretical background, hypotheses, and research model. Section 4 then expounds on the research method. Section 5 contains the empirical results obtained from the analysis of the SEM method. The last section presents the conclusions, describes the limitations of the study, discusses the contributions and implications for future research, and provides some closing remarks.

\section{LITERATURE REVIEW}

This study is based on three research streams in the literature on IT business use: (1) the components and practices of
ITG (Caluwe and De Haes 2019; Lunardi et al. 2017); (2) the BITA model and its measurement (Gerow et al. 2014; Jia et al. 2018; Zhang et al. 2018), and (3) the relationship between ITG and BITA (De Haes and Van Grembergen 2009; Héroux and Fortin 2018). As discussed in the introduction, there is still a need for knowledge that involves the measurement of ITG practices and their ability to generate BITA.

This study was based on recent articles that reviewed the literature on each construct. In the case of ITG, the definitions and mechanisms or practices of ITG studied by Levstek, Hovelja and Pucihar (2018) were reviewed. The research gap raised by Caluwe and De Haes (2019) on the uncertainty of ITG consequences was also taken into account. In the case of BITA, the 5W1H (When, Who, What, Why, Where, How) analysis by Zhang, Chen and Luo (2018) was considered to understand BITA from the perspective of the company's architecture. Likewise, this study analyzes the four main research topics on BITA (model, measurement, background, and dynamics) suggested by Jia, Wang and Ge (2018).

\subsection{IT Governance (ITG)}

Academic and practitioner literature has addressed the issue of ITG since the 1990s, focusing on two perspectives, one that analyses it as a derivation of corporate governance and another that sees it as a determining factor of the alignment between business objectives and IT (Balocco et al. 2013). ITG can be understood as part of corporate governance that enables the IT function to add value to the business by controlling the risks associated with IT processes and making better use of available technology resources (IT Governance Institute 2003). However, ITG is not an easy notion to understand, and previous research has examined different aspects of ITG in various contexts that often have different interpretations (Buchwald et al. 2014).

In a longitudinal study on large enterprises, Peterson (2004) offered a roadmap for the IT Governance Assessment Process (ITGAP), which has four stages: "(1) Describe and assess ITG value drivers, (2) Describe and assess the differentiation of IT decision-making authority for the portfolio of IT activities, (3) Describe and assess the capabilities of ITG, and (4) Describe and assess IT value realization" (Peterson 2004, p. 20).

Weill and Ross (2004) defined ITG in the following terms: "Specifying the decision rights and accountability framework to encourage desirable behavior in the use of IT" (p. 8). According to these authors, ITG is a framework of interaction among three key components: the first is known as structures that derive from business units, functions, roles, and responsibilities for proper IT decision-making. The second is processes, which refer to the design of procedures for implementing management following IT strategies and policies. The last component is relational mechanisms, which are considered the devices that look for opportunities to guarantee the effectiveness of ITG implementation.

Derived from studies by Van Grembergen et al. (2004), Peterson (2004), Weill and Ross (2004) and De Haes (2007), De Haes and Van Grembergen (2008) argued that, "IT governance can be deployed using a mixture of various structures, processes, and relational mechanisms" (p. 1). ITG structures "include 
structural (formal) devices and mechanisms for connecting and enabling horizontal, or liaison, contacts between business and IT management (decision-making) functions" (Peterson 2004, p. 14). ITG processes have to do with "formalization and institutionalization of strategic IT decision-making or IT monitoring procedures" (Peterson 2004, p. 15). ITG relational mechanisms are understood as "the active participation of, and collaborative relationships among, corporate executives, IT management, and business management" (Peterson 2004, p. 15).

Caluwe and De Haes (2019) set out to find knowledge gaps in board-level ITG at the, summarizing existing research and identifying opportunities for future research. Such a study found that at the level of ITG structures there is extensive research on background and consequences. It concluded that there is little research available on ITG processes, as well as on ITG relational mechanisms. This suggests that while ITG structures are quite clear and described in detail in previous research, little was found about ITG processes and relational mechanisms (Caluwe and De Haes 2019). This study leverages this gap and seeks to study and measure ITG in its three dimensions together (structures, processes, and relational mechanisms).

\subsection{Business-IT Alignment (BITA)}

BITA is defined as the degree of alignment between IT and business strategy (Jia et al. 2018) and has been a concern of senior management for decades (Queiroz 2017). This can be seen, for example, in the study by Luftman et al. (2013) in which they state that BITA has consistently been ranked as one of the top three challenges for scholars, IT professionals, and business executives over the past three decades, showing that BITA remains the ultimate goal of organizations. This is not so easy to achieve and, as such, it has become the main concern of IT management in the US and Europe, the second in Latin America and the sixth in Asia. However, despite much research, the effect of IT strategic alignment on organizational performance remains evident (Sabherwal et al. 2001; Yayla and Hu 2012; Gerow et al. 2015, 2016), but with mixed results in the literature (Queiroz 2017).

In a bibliometric review of literature on BITA, Jia et al. (2018) identify four relevant BITA research factors, model, measurement, background, and dynamics. The first factor referred to is the BITA model. In a widely publicized study, Henderson and Venkatraman (1993) characterized the strategic alignment model (SAM) as describing all possible alignment relationships among four key components: business strategy, IT strategy, business infrastructure and processes, and IT infrastructure and processes.

The second BITA factor analyzed is how alignment is measured. There have been many methods for measuring BITA but the existing ones are based on a static perspective. In essence, each method is different and can lead to different types of results (Jia et al. 2018). For example, Luftman (2000) designed a widely publicized survey based on the SAM model, while Bergeron et al. (2004) present a form of alignment measurement that attempts to explain the impact of various factors on alignment and at the same time its impact on organizational performance.
The third factor is the BITA background; Jia et al. (2018) identify numerous BITA antecedents that subsequently group into four dimensions (social, cultural, strategic, and structural). Within the various BITA antecedents studied, some ITG practices can be found but these studies deal with individual effects of some ITG practices on BITA and not the joint effect of ITG practices (structures, processes, and relational mechanisms) on BITA.

The fourth factor is the BITA dynamics; Chan and Reich (2007) argued that there are two basic ways of looking at alignment. The first way is to appreciate alignment as a continuous process, which is subject to variations resulting from decisions made, adjustment of adopted strategies over time, and improvement of IT management capabilities. The second way is alignment as a final state, which is conceived as resulting from either action taken or the strategies the organization has planned.

Thus, in this research, BITA is reviewed from the perspective of alignment measurement, taking into account the proposal of Bergeron et al. (2004) and not that of Luftman (2000) since ITG maturity is one of its dimensions, causing endogeneity. From the perspective of BITA dynamics, this study, given its cross-sectional nature, looks at the current state of alignment in the organization and not its continuous process.

\subsection{Relationship between ITG and BITA}

In different studies (De Haes and Van Grembergen 2004; Van Grembergen 2004; Van Grembergen et al. 2004; Van Grembergen and De Haes 2008), the authors collected previous studies and suggested that ITG can be implemented through a combination of structures, processes, and relational mechanisms. They then suggested that there is a relationship between ITG and BITA (De Haes and Van Grembergen 2009).

Some authors have taken up in many ways the formulation of De Haes and Van Grembergen (2009) on the implementation of TI governance practices. Kuruzovich, Basselier, and Sambamurthy (2012) assessed how the strategic importance of IT influences the governance practices of IT involving the board of directors and how they affect IT alignment. Besides, Ping-Ju Wu et al. (2015) examined how ITG mechanisms and strategic alignment influence organizational performance.

Asante (2010) studied how the ITG structures (Focused, Decentralized, and Federal) established by Weill and Ross (2004) impact the maturity of IT strategic alignment, using the model of Luftman (2000). Harguem, Karuranga and Mellouli (2014) empirically proved through a quantitative study in US companies that ITG mechanisms positively affect the organization's global IT management capabilities, contributing to improved strategic alignment that could be reflected in the organization's performance.

As can be seen, the authors have used each of the ITG practices separately. There is consensus that organizations should use ITG mechanisms, but few researchers attempt to describe and provide a complete explanation for ITG mechanisms or practices (Levstek et al. 2018). For this reason, this study attempts to assess ITG practices or mechanisms (structures, processes, and relational mechanisms) together to observe their impact on BITA. 


\section{THEORETICAL BACKGROUND, HYPOTHESIS, AND RESEARCH MODEL}

Seminal researchers have argued that organizations that actively seek to plan and implement ITG structures perform significantly better than those that do not consider ITG (Van Grembergen and De Haes 2008; Weill et al. 2002; Weill and Ross 2004). Other authors argue that alignment, communication, and the relationship between IT and business are important aspects to consider in the implementation of ITG (Alreemy et al. 2016).

In a qualitative exploratory study, Buchwald et al. (2014) affirmed that the greater the success of ITG, the greater the alignment of business and IT objectives. De Haes and Van Grembergen (2009) suggested that the maturity of BITA is greater when organizations apply a combination of mature ITG practices (structures, processes, and relational mechanisms).

Therefore, it can be assumed that better ITG development will result in the firm's ability to achieve a better level of BITA. Under the previous arguments, the following hypothesis can be formulated:

\section{H1: IT governance has an impact on business-IT alignment}

From the above description, the characteristics of the organization could influence the specified relationship. In this regard, previous researchers have argued that "it is acknowledged that the use of ITG practices might be different in different types of industries" (De Haes and Van Grembergen 2009, p. 125). Similarly, other researchers on strategic alignment (Chan et al. 2006; Chan and Reich 2007; Luftman et al. 2008; Tallon and Pinsonneault 2011) argued that this relationship is conditioned by industry type. This leads to the following hypothesis:

H2: There is a difference in the impact of IT governance on business-IT alignment depending on industry type.

Small and medium-sized enterprises (SMEs) evolving in a dynamic environment are characterized by an unpredictable market and technological change and face more pressures than large companies in the same environment (Raymond et al. 2019). Concerning ITG, most theories and frameworks have been criticized as being more appropriate to large enterprises and less so to SMEs (Bergeron et al. 2015). In fact, in their study on the effect of ITG on organizational performance, Ping-Ju Wu et al. (2015) stated that ITG is most practiced in large enterprises. Some authors argue that IT adoption is faster in large firms than in SMEs because large firms assume that ITG practices or mechanisms create value for the business, while in SMEs, decision-making is primarily focused on one person (Levstek et al. 2018).

In terms of alignment, there are different views. Chan et al. (2006) found that firm size is related to BITA, but not in all industry types. Chan and Reich (2007) suggested that certain components of alignment occur in small rather than medium-sized firms. Gutiérrez, Orozco, and Serrano (2009) concluded that the factors considered necessary to achieve alignment are relevant to all organizations, regardless of their size. Charoensuk, Wongsurawat, and Khang (2014) found that company size acts as a moderator rather than a predecessor to BITA. Shihab and Rahardian (2017) found that organizations of different sizes differ significantly in their approach to alignment. The above information leads to the following hypothesis:
H3: There is a difference in the impact of IT governance on business-IT alignment depending on company size.

The purpose of this research is to further explain the effects of ITG implementation on BITA, as shown in Figure 1. The proposed framework involves examining the interrelationship between two fundamental structures. First, about ITG practices, this study is based on the approach of De Haes and Van Grembergen (2009), which involves three basic elements: structures, processes, and relational mechanisms. These ITG practices correspond to variables that measure maturity, "This maturity assessment was based on a generic maturity model as proposed by the IT Governance Institute (2003), providing a scale from 0 (non-existent) to 5 (optimized)" (De Haes and Van Grembergen 2009, p. 127).

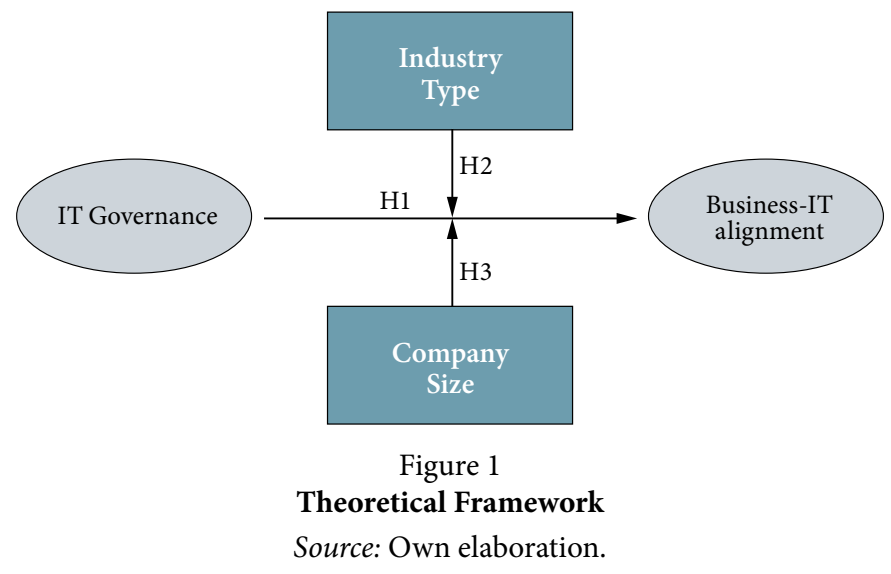

Secondly, in the case of BITA, this study employs a measurement model with a holistic approach as proposed by Bergeron et al. (2004), which evaluates BITA from four perspectives: business strategy, IT strategy, business structure, and IT structure. The business strategy dimension includes a 7-point scale instrument called Strategic Business Orientation (STROBE), developed by Venkatraman (1989) to measure strategic orientation, and consists of six components: aggressiveness, analysis, defensiveness, futurity, proactivity, and riskiness.

Based on the study by Damanpour (1991), Bergeron et al. (2004) argued that the most common structural dimensions in organizational theory and Information Systems studies are formalization, centralization or administrative intensity, professionalization, specialization, and vertical differentiation. Bergeron et al. (2004) suggested that IT strategy includes two components, one of which, the analysis of the IT environment, refers to how the firm can detect and react to technological changes compared to its competitors. The second concerns the strategic use of IT and measure how IT implementation increases quality, competitiveness, and business performance.

According to Bergeron et al. (2004), the IT structure has two components. The first is IT planning and control, which shows how the company manages its IT function, resources, and infrastructure concerning its competitors. The second component is IT acquisition and implementation, which refers to how the firm manages the selection and introduction of new IT applications. 


\section{METHOD}

\subsection{Research design}

This research studies the phenomenon of the specified relationship at a particular time and is therefore considered cross-sectional (Saunders et al. 2019). The study aims to determine the impact of ITG on BITA, based on the relationship suggested by De Haes and Van Grembergen (2009) in their case study of the Belgian financial sector, and it is, therefore, necessary to include analysis and hypothesis testing in this research design.

This research used the SEM as an alternative to estimate the effects and relationships among multiple variables (Kline 2016). SEMs allow us to suggest the type and direction of the relationship expected to be found among variables, seeking to estimate the parameters associated with the proposed theoretical relationships (Ruiz et al. 2010). This research takes an SEM technique with Confirmatory Factor Analysis (CFA) as a mechanism to show the analysis of the theoretical relationships between ITG and BITA.
The SEM technique includes six steps for implementation: (1) specification, (2) identification, (3) measure selection and parameter estimation, (4) model estimation and fit evaluation, (5) model re-specification and (6) result interpretation (Kline 2016). In general, in the specification phase, the researcher draws a diagram model using a standard set of graphic symbols. However, the researcher can also describe the model through a series of equations that define the model's parameters and the assumed relationships among variables (Kline 2016).

Byrne (2010) argued that schematic representations of models are called causal diagrams because they provide a visual representation of the relationships among variables that will be used in the study. The general SEM model comprises two sub-models, a measurement model, and a structural model. The structural model defines the relationships among non-observable variables, including exogenous latent variables (ITG practices in this case) and endogenous latent variables (BITA in this case), as shown in Figure 2.

Exogenous latent variables

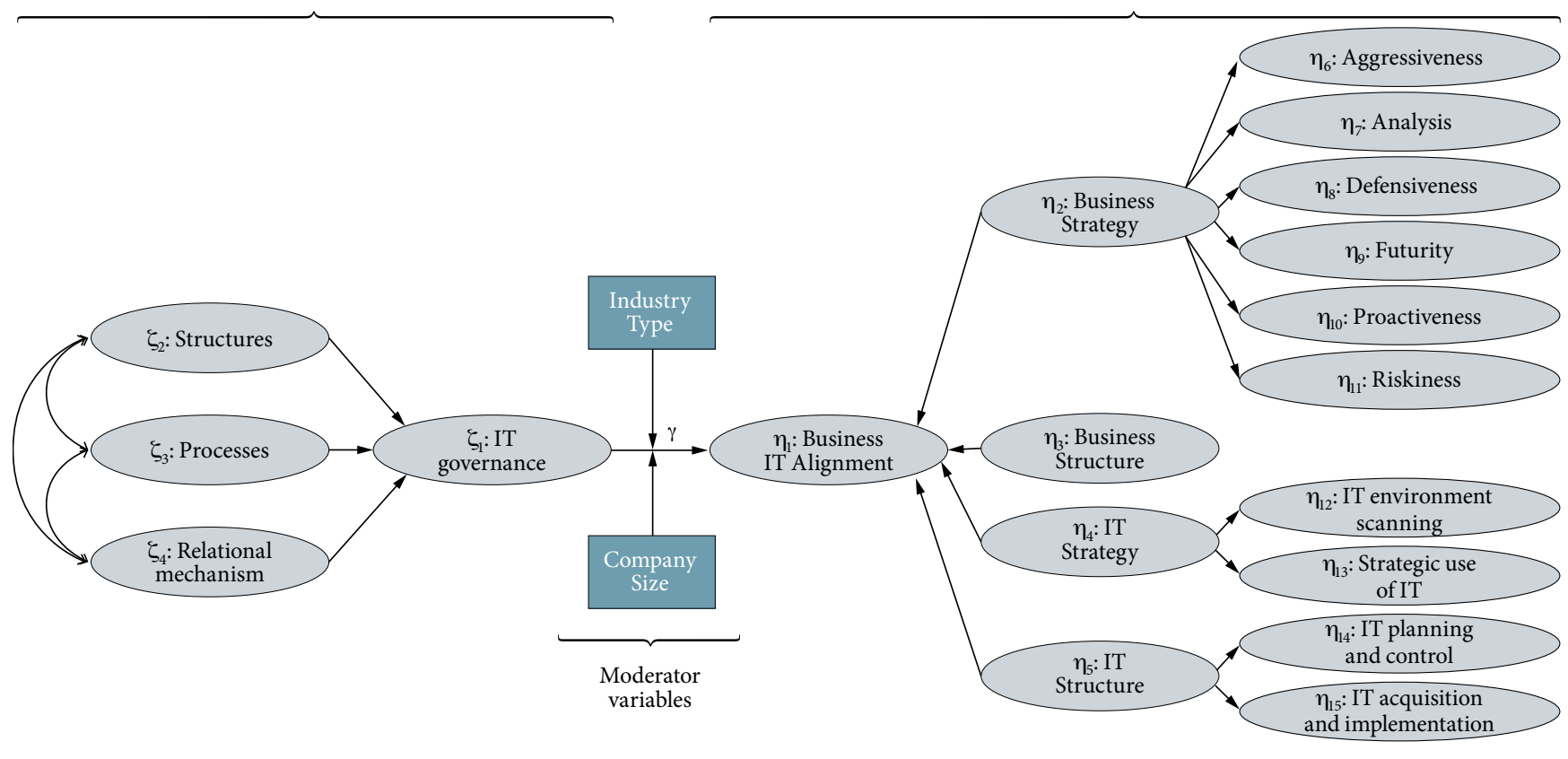

Figure 2

Structural Model

Source: Own elaboration.

The measurement model defines the relationships between observed and unobserved variables, providing the link between scores on a measurement instrument (observed indicator variables) and the underlying model for measuring variables (unobserved latent variables) (Byrne 2010).

Coltman et al. (2008) argued that there are three theoretical considerations in deciding whether a measurement model is reflective or formative. The first concerns the nature of the construction. Therefore, in the reflective model, the latent variable exists independently of measurements. In contrast, in the formative model, the latent variable is a combination of indicators.
The second consideration is to focus on the direction of causality. In reflective models, causality flows from latent variables to indicators and in the formative model, it flows in the opposite direction. The last consideration is the characteristics of indicators. In reflective models, a change in the latent variable precedes a change in the indicator; elements are expressed by the latent variable and share common themes. In contrast, in training models, indicators define latent variables and do not necessarily share common themes. This research adopts a reflexive model between latent variables and indicators, based on the proposal of Bergeron et al. (2004) in their research model. 
The design of this research took into account the moderating variables that regulate the degree of intensity with which one variable impacts another (Chion and Charles 2016). For this research, the moderating variables are industry type and company size. Chan et al. (2006) argued that there are several precedents that the importance of alignment depends on the industry in which the organization operates and that the size of the organization is associated with alignment. Chan and Reich (2007) suggested that communication and coordination in small firms are easy to implement, so these firms may tend to align themselves better than medium-sized firms, where there may be less evidence of alignment.

This research aims to address the different sizes of enterprises; ITG studies have focused primarily on large enterprises, but this does not mean that ITG does not exist in SMEs (Bergeron et al. 2015). In fact, most SMEs use IT for their basic needs but show a tendency to use it for more advanced activities (Mardikyan 2010). However, implementing ITG in the context of SMEs is a complex effort, mainly due to their nature and structure (Olutoyin and Flowerday 2016).

\subsection{Measurement}

\section{A. IT GOVERNANCE (ITG)}

To measure ITG, this study was based on the generic model of ITG maturity (De Haes and Van Grembergen 2009; IT Governance Institute 2003), in which 12 items are used to evaluate structures (e.g., the existence of a steering committee at executive or senior management level responsible for determining business priorities in IT investments), 11 items to evaluate processes (e.g., the existence of regular self-assessments or independent assurance activities on IT governance and control), and 10 to evaluate relational mechanisms (e.g., the existence of systems to share and distribute knowledge of ITG framework, responsibilities, tasks, etc.). Then, using a 6-point scale (0- Non-existent, 1- Initial/ad hoc, 2- Repeatable but intuitive, 3- Defined process, 4- Managed and measurable, and 5- Optimized), the respondent indicates the extent to which each ITG practice is applied by the enterprise.

\section{B. Business-IT ALIGNMENT (BITA)}

To measure BITA, this study was built on the holistic model by Bergeron et al. (2004), which has four dimensions (business strategy, IT strategy, business structure, and IT structure). The first dimension of the model is the business strategy, which attempts to evaluate the strategy carried out rather than the strategy planned, focusing on the idea of deploying the resources needed to achieve business objectives. Bergeron et al. (2004) based their analysis on the proposal of Venkatraman (1989) to measure strategic orientation on six elements: aggressiveness (4 items), analysis (6 items), defensiveness ( 4 items), futurism (5 items), proactivity (5 items), and riskiness (5 items). Then, using a 7 -point ordinal scale (1Strongly disagree, ..., 7- Strongly agree), the respondent indicates the extent to which the company meets each criterion.

The second dimension is the business structure measured by five variables. The first is formalization, which can be measured by the number of rules, procedures, and activities that are written and documented. The second is administrative intensity, also known as centralization, calculated by the relationship between the number of managers and the number of employees. The third element is professionalization, calculated by dividing the number of professionals by the number of employees. The fourth is related to specialization, also known as horizontal differentiation, which includes the number of different job titles in the organization chart. The last one is vertical differentiation and refers to the number of organizational levels that are below the CEO.

The third dimension suggested by Bergeron et al. (2004) is the IT strategy, which is measured from two components. The first is IT environment scanning (4 items), which attempts to explain the organization's capacity to detect and respond to changes generated by competitors. The second component is the strategic use of IT (6 items), trying to synthesize the extent to which the organization uses IT to increase the quality of its products and services and improve competitiveness and productivity. Then, using a 7-point ordinal scale (1- Strongly disagree, ..., 7- Strongly agree), the respondent indicates the extent to which the company meets each criterion.

Finally, the fourth dimension is the IT structure, which is made up of two components. One is IT planning and control (9 items), which includes activities designed to observe the IT management function, IT resources and IT infrastructure. The other component is IT acquisition and implementation (9 items), which refers to activities that explain the selection and introduction of new IT applications into the business. Then, using a 7-point ordinal scale (1- Strongly disagree, ..., 7- Strongly agree), the respondent indicates the extent to which each criterion is met by the enterprise.

\section{Moderating variables}

This research takes the form of categorizing company size according to Ping-Ju Wu et al. (2015), in which small companies are those with less than 100 employees, medium companies are those with 100 to 1000 employees, and large companies are those with more than 1000 employees.

Mardikyan (2010) argued that there are significant differences in the use of IT among different industry types. Then, this study will use ten industry types, to wit, manufacturing, services, IT, health, education, energy, customer products, transportation, retail, and chemical-pharmaceutical.

\section{Data collection}

This research used an instrument developed by other researchers (Bergeron et al. 2004; IT Governance Institute 2003). The instrument was translated into Spanish under the supervision of a reviewer based on the indices proposed by the authors. The questionnaire was tested with a group of 100 people to observe different aspects. Initially, it was observed that the respondents had no comprehension problems because the questions and instructions were provided both in the invitation to participate and on the survey website and were very clear to them. Finally, it was demonstrated that the information was stored comprehensively and that the participant could know that his or her answers were effectively saved. 
Based on the database of 26,533 companies that report to the Superintendence of Companies in Colombia in the SIREM system as of 2015, 1,500 companies were randomly selected and contacted by phone, email, or in-person to take part in the study. In this way, their existence and contact information were confirmed and it was validated that they have an IT department or an area that fulfills the appropriate functions of IT management to evaluate their interest in participating in this research (Kaur et al. 2011).

The instrument was coded and entered into an institutional web platform to generate an individual link to the questionnaire for each company; then, on the same platform, a list of companies invited to participate was created with their contact emails. The questionnaire was divided into four sections and the website was programmed in such a way that it was impossible to save the data from each section until all the questions were answered. First, of the 1,500 companies selected, 945 were verified and sent specific information to the emails, including a letter of introduction to the study, an informed consent form, and the individual link to the survey. In the first round, 126 surveys were completed. In a second round, 829 emails were sent to the remaining companies, eliciting 107 responses, with a total of 333 responses at the time.

To complete the sample, awareness-raising work was carried out with associations and chambers of commerce to contact companies interested in participating in the research. In this third round, after several days of work in which a group of 339 companies completed the questionnaire, 672 companies ended up participating in the study. The data were collected from October 2016 to February 2018 on a web platform, from which they were coded and loaded into a data file in SPSS, version 24 for statistical analysis and in AMOS add-on, version 24 , for reviewing the structural equation model.

\section{RESULTS}

Initially, the quality of the measures used in the relationship model was determined to contrast the causal relationships of the conceptual model. The phases of application of the SEM technique are as follows: (a) specification, (b) identification, (c) measure selection and data collection, (d) model estimation (evaluation of model fit and interpretation of parameter estimates), (e) re-specification and (f) result interpretation (Kline 2016).

\subsection{Review of the Measures Involved in the Model}

To perform an analysis of the measures used in the model, a review of reliability, convergent validity, and discriminant validity was performed (Table 1). Reliability was obtained through Cronbach's alpha ( $\alpha$ ), achieving indicators above the recommended limits in all variables (greater than 0.7 ). Regarding convergent validity, the indicators of composite reliability (CR) and mean extracted variance (AVE) were used, which show favorable results (higher than 0.7 and 0.5 , respectively) and ensure the consistency of the measurements used (Farooq 2016).

Likewise, discriminant validity was analyzed to verify that each variable shares more variance with its indicators than with other variables. To this end, the square root of the AVE was extracted and placed in the diagonal of Table 1 . The result of the values found in the diagonal is higher than the correlations among the variables reflected in the values outside the diagonal, which supports the discriminant validity of the measures used (Kline 2016).

Table 1

Reliability and Validity Indexes

\begin{tabular}{|c|c|c|c|c|c|c|c|c|c|c|c|c|c|c|c|c|}
\hline \multirow{2}{*}{ Construct } & \multirow{2}{*}{$\begin{array}{c}\text { Reliability } \\
a\end{array}$} & \multicolumn{2}{|c|}{$\begin{array}{c}\text { Convergent } \\
\text { Validity }\end{array}$} & \multicolumn{13}{|c|}{ Discriminant Validity } \\
\hline & & CR & AVE & 1 & 2 & 3 & 4 & 5 & 6 & 7 & 8 & 9 & 10 & 11 & 12 & 13 \\
\hline 1. Structures & 0.98 & 0.98 & 0.78 & 0.88 & & & & & & & & & & & & \\
\hline 2. Processes & 0.97 & 0.97 & 0.74 & 0.30 & 0.86 & & & & & & & & & & & \\
\hline 3. Relational Mechanisms & 0.97 & 0.97 & 0.75 & 0.26 & 0.46 & 0.86 & & & & & & & & & & \\
\hline 4. Aggressiveness & 0.95 & 0.95 & 0.82 & 0.05 & 0.01 & -0.03 & 0.90 & & & & & & & & & \\
\hline 5. Analysis & 0.96 & 0.96 & 0.80 & 0.04 & 0.02 & 0.00 & 0.80 & 0.90 & & & & & & & & \\
\hline 6. Defensiveness & 0.94 & 0.94 & 0.81 & 0.03 & 0.06 & 0.02 & 0.75 & 0.75 & 0.90 & & & & & & & \\
\hline 7. Futurity & 0.95 & 0.95 & 0.79 & 0.04 & -0.01 & -0.02 & 0.67 & 0.82 & 0.63 & 0.89 & & & & & & \\
\hline 8. Proactiveness & 0.94 & 0.94 & 0.75 & 0.01 & 0.00 & -0.04 & 0.60 & 0.70 & 0.53 & 0.78 & 0.87 & & & & & \\
\hline 9. Riskiness & 0.94 & 0.94 & 0.77 & 0.01 & 0.02 & -0.01 & 0.71 & 0.68 & 0.65 & 0.59 & 0.54 & 0.88 & & & & \\
\hline 10. IT environment scanning & 0.94 & 0.94 & 0.77 & 0.02 & 0.04 & 0.00 & 0.65 & 0.64 & 0.61 & 0.56 & 0.52 & 0.60 & 0.88 & & & \\
\hline 11. Strategic use of IT & 0.96 & 0.96 & 0.78 & 0.03 & 0.05 & 0.00 & 0.57 & 0.59 & 0.56 & 0.52 & 0.48 & 0.56 & 0.83 & 0.89 & & \\
\hline 12. IT planning and control & 0.97 & 0.97 & 0.77 & 0.05 & 0.03 & 0.01 & 0.59 & 0.61 & 0.58 & 0.55 & 0.51 & 0.55 & 0.85 & 0.75 & 0.88 & \\
\hline 13. IT acquisition and implementation & 0.97 & 0.97 & 0.78 & 0.02 & 0.01 & 0.01 & 0.54 & 0.56 & 0.53 & 0.49 & 0.46 & 0.50 & 0.77 & 0.69 & 0.87 & 0.88 \\
\hline
\end{tabular}

a: Cronbach's Alpha; CR: Composite Reliability; AVE: Average Variance Extracted

Source: Own elaboration. 


\subsection{Analysis of the Structural Model}

The six phases of application of the SEM technique are described below. The first phase is known as the specification phase and establishes the hypothetical relationship between latent and observed variables and is represented graphically (Figure 3 ).

The second step of the SEM technique is identification. A model is identified if it is theoretically possible to provide a unique estimate for each of the model parameters; otherwise, the model is not identified (Kline 2016). There are several general rules for identifying a model, one of which, for example, is the rule of degrees of freedom (df), which states that the model's degrees of freedom must be greater than or equal to zero $(\mathrm{dfM} \geq 0)$. Since $\mathrm{dfM}=4255$ (a value greater than zero), the model is identified.
Before analysis and model estimation, it is advisable to examine all variables in order to assess the quality of the database. The first problem to address is the sample size; determining its requirements for SEM is often a challenge researchers face (Wolf et al. 2013). Some authors have suggested that sample size depends on the desired power, bias, and evaluation of the null hypothesis and the complexity of the model; if the model is more complex, a larger sample is required (MacCallum et al. 1996; Iacobucci 2010; Wolf et al. 2013). In this research, the sample size is 672 which is considered appropriate for improving statistical power, "For studies with moderate to large df, reasonable power is achieved with moderate sample sizes, and very high power is achieved with large samples. For instance, with $\mathrm{df}=100$, power is well above 0.90 if $\mathrm{N}$ is 200 or more" (MacCallum et al. 1996, p. 139).
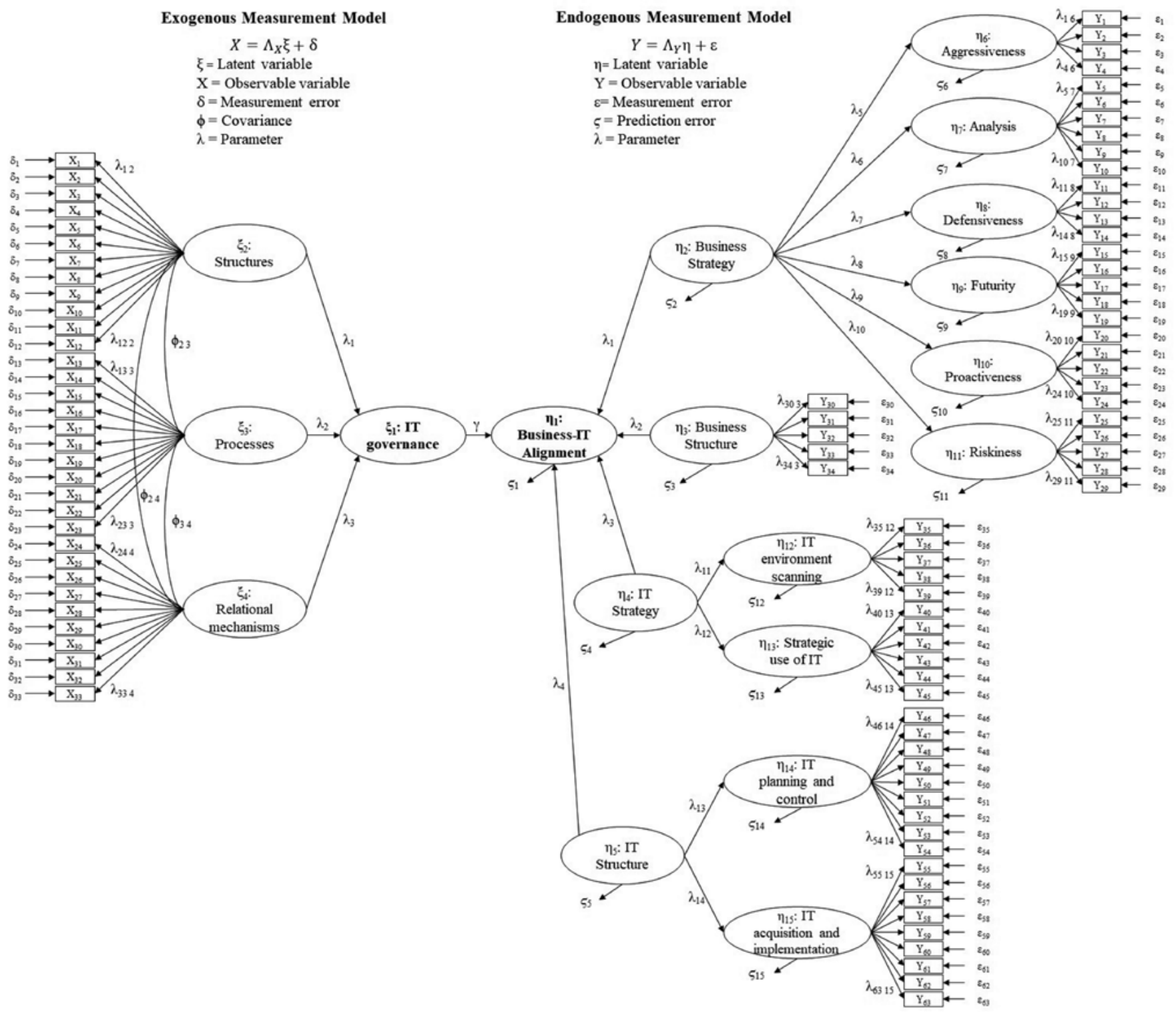

Figure 3

Research Model

Source: Own elaboration. 
Another aspect to consider is multicollinearity among variables, where highly correlated variables are considered redundant. In this research, collinearity tests were performed; the multiple squared correlations $\left(\mathrm{R}^{2}\right)$ between each variable and the others were initially calculated, obtaining a maximum value of 0.0043 that is lower than the reference value $(>0.90)$ for extreme multivariate collinearity (Kline 2016). Also, collinearity statistics were calculated for each of the independent variables (Table 2). Tolerance points to the proportion of the total standardized variance that is unique and not explained by other variables (values $<0.10$ indicate extreme multivariate collinearity), while the variance inflation factor (VIF), whose reference value is VIF $>10$, may indicate that the variable may be redundant (Kline 2016). As can be seen, multi-collinearity occurs in neither case. Finally, the results of univariate normality tests show that of 94 observable variables, only two did not have adequate values of asymmetry and kurtosis. Concerning multivariate normality, AMOS provided the result of the Mardia's coefficient (452.1) and showed that there is no multivariate normality. To counteract the absence of normality, the sample size is sufficient to demonstrate that the impact of the sampling error could be minimal (Kline 2016).
Table 2

Collinearity Statistics

\begin{tabular}{lcc}
\hline \multicolumn{1}{c}{ Independent Variable } & Tolerance & Variance Inflation Factor (VIF) \\
\hline Structures & 0.89 & 1.12 \\
Processes & 0.75 & 1.33 \\
Relational Mechanisms & 0.77 & 1.30 \\
\hline
\end{tabular}

Source: Own elaboration.

In the estimation phase, the values of the unknown parameters are determined, as well as their respective measurement error. The parameter estimation process was carried out under the Maximum Likelihood Estimation (MLE), which is considered efficient and not biased when multivariate assumptions of normality are not found. In this phase, the results of the model goodness-of-fit were obtained and some modifications were made to the specification model to improve the fit. Measures of fit quality can be of three types: absolute fit, incremental fit, and measures of parsimony fit. The model results without the moderating effect achieve satisfactory fit to data

Table 3

Goodness-of-fit Measures

\begin{tabular}{|c|c|c|c|c|c|c|}
\hline \multirow{2}{*}{ Measure } & \multirow{2}{*}{ Index } & \multirow{2}{*}{ Shorthand } & \multirow{2}{*}{ Value } & \multicolumn{3}{|c|}{ Rating } \\
\hline & & & & Low & Medium & High \\
\hline \multirow{14}{*}{ Absolute Fit } & Chi-square & CMIN & 5898.20 & $\mathrm{X}$ & & \\
\hline & Minimum Discrepancy (Normed Chi-Square) & CMIN/DF & 1.39 & & & $\mathrm{X}$ \\
\hline & Non-Centrality Parameter & NCP & 1643.20 & $\mathrm{X}$ & & \\
\hline & Scaled Non-Centrality Parameter & SNCP & 2.45 & $\mathrm{X}$ & & \\
\hline & Goodness-of-Fit Index & GFI & 0.84 & & $\mathrm{X}$ & \\
\hline & Adjusted Goodness-of-Fit Index & AGFI & 0.84 & & $\mathrm{X}$ & \\
\hline & Root Mean Square Residual & RMR & 0.08 & & & $\mathrm{X}$ \\
\hline & Akaike Information Criterion & AIC & 6318.20 & $\mathrm{X}$ & & \\
\hline & Expected Cross Validation Index & ECVI & 9.07 & $\mathrm{X}$ & & \\
\hline & Browne-Cudeck Criterion & $\mathrm{BCC}$ & 6387.47 & $\mathrm{X}$ & & \\
\hline & Bayes Information Criterion & BIC & 7265.35 & $\mathrm{X}$ & & \\
\hline & Root Mean Square Error of Approximation & RMSEA & 0.02 & & & $\mathrm{X}$ \\
\hline & Hoelter .05 Index & HOELTER05 & 502 & & & $\mathrm{X}$ \\
\hline & Hoelter .01 Index & HOELTER01 & 509 & & & $\mathrm{X}$ \\
\hline \multirow{5}{*}{$\begin{array}{l}\text { Comparative or } \\
\text { Incremental Fit }\end{array}$} & Tucker-Lewis Index & TLI or Rho 2 & 0.98 & & & $\mathrm{X}$ \\
\hline & Normed Fit Index & NFI or Delta 1 & 0.93 & & & $\mathrm{X}$ \\
\hline & Relative Non-centrality Fit Index & RFI or Rho 1 & 0.92 & & & $\mathrm{X}$ \\
\hline & Incremental Fit Index & IFI or Delta 1 & 0.98 & & & $\mathrm{X}$ \\
\hline & Comparative Fit Index & CFI & 0.98 & & & $\mathrm{X}$ \\
\hline \multirow{4}{*}{ Parsimonious Fit } & Parsimony-Adjusted NFI & PNFI & 0.90 & & & $\mathrm{X}$ \\
\hline & Parsimony-Adjusted CFI & PCFI & 0.95 & & & $\mathrm{X}$ \\
\hline & Parsimony Goodness of Fit Index & PGFI & 0.81 & & $\mathrm{X}$ & \\
\hline & Parsimony Ratio & PRATIO & 0.97 & & & $\mathrm{X}$ \\
\hline
\end{tabular}

Source: Own elaboration using AMOS indexes. 
as shown in Table 3 . The minimum discrepancy ratio CMIN/ DF (5898.2/4255) takes a value of 1.39 , proof of the statistical significance of the model; the root mean square error of approximation (RMSEA) shows a value of 0.02 and the goodness-of-fit index (GFI) takes a value of 0.84 . As for the incremental fit indexes, they are all above the cut-off value (0.90), with the Comparative Fit Index (CFI) taking a value of 0.97 and the Normalized Fit Index (NFI) taking a value of 0.93. As for the parsimony fit indexes, most of them are above the ref- erence value (0.90). This shows that the ratio model estimates are above the recommended threshold for a good fit (Schreiber et al. 2006).

To verify the relative capacity of the model to explain the total variance of BITA, the determination coefficient $\left(\mathrm{R}^{2}\right)$ was used, obtaining a result of 0.955 . This value indicates that the joint explanatory capacity of the variables is high since they represent $95.5 \%$ of the variability of BITA. The path coefficients for the research model are shown in Figure 4.

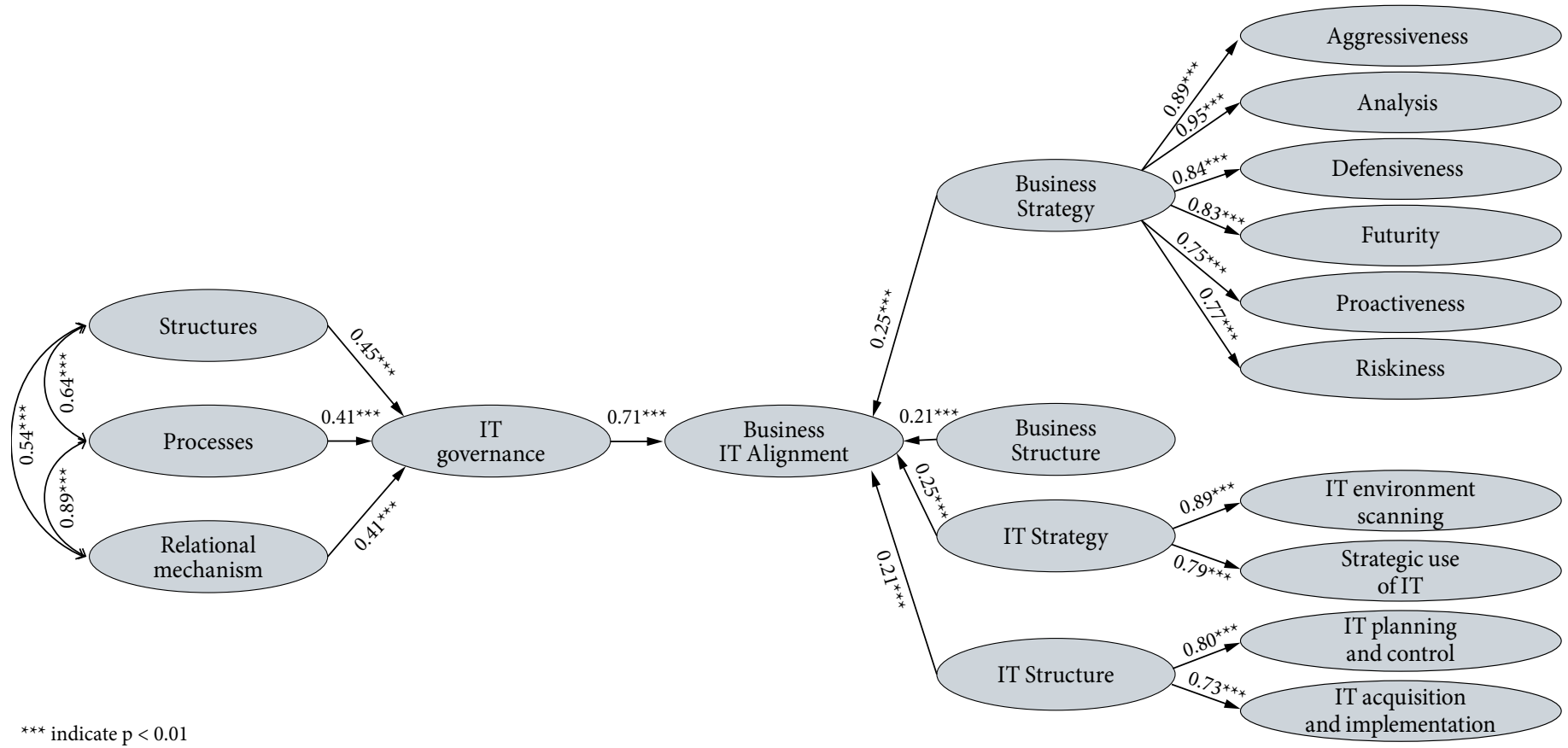

Figure 4

Research Model Results

Source: Own elaboration.

Once the good fit of the model was demonstrated, the resulting relationships were analyzed to verify the validity of the hypotheses and thus determine their predictive capacity (Table 4). Initially, the strong and direct relationship between ITG and BITA is shown (0.71), which is significant for a p-value $<0.01$ and allows rejecting $\mathrm{H}_{0}$ and accepting $\mathrm{H} 1_{\mathrm{a}}$.

The relationship model includes moderating variables that try to explain whether there are differences in the relationship between different sizes and types of companies. For this purpose, a multi-group analysis was carried out to test hypotheses 2 and 3. In this regard, the data set was divided into two variables (company size and industry type) to estimate whether the proposed relationship behaved differently depending on the effect that the moderating variables might have. For this, the sample was distributed into several groups depending on the moderating variables; the results of the parameters and adjustment are shown in Table 4.

The results show that the parameters vary in the case of industry type ranging from 0.68 to 0.78 with the same level of significance ( $p$-value $<0.01$ ); in the case of company size, they are in the range of 0.58 to 0.62 with the same level of significance ( $\mathrm{p}$-value $<0.01$ ). The chi-square test of ratios was applied to $\mathrm{H} 2$ and $\mathrm{H} 3$, i.e., if there is no difference in the moderation of the impact of ITG on BITA by industry type and company size, respectively. In the first case, the value was 0.999 and in the second case, 0.998 , which certified the non-rejection of $\mathrm{H} 2{ }_{0}$ and $\mathrm{H} 3_{0}$. 
Table 4

Model Results

\begin{tabular}{|c|c|c|c|c|c|c|c|c|c|c|}
\hline \multirow{3}{*}{ Results } & \multirow{2}{*}{$\begin{array}{l}\text { Default } \\
\text { Model }\end{array}$} & \multicolumn{6}{|c|}{ Industry Type } & \multicolumn{3}{|c|}{ Company Size } \\
\hline & & Manufacturing & Services & IT & $\begin{array}{c}\text { Healthcare/ } \\
\text { Medical }\end{array}$ & Education & Retail & Small & Medium & Large \\
\hline & $n=672$ & $n=109$ & $n=100$ & $n=101$ & $n=106$ & $n=103$ & $\mathrm{n}=104$ & $\mathrm{n}=\mathbf{3 4 0}$ & $\mathrm{n}=\mathbf{2 2 8}$ & $n=104$ \\
\hline CMIN/DF & 1.39 & 1.67 & 1.88 & 1.83 & 1.72 & 1.88 & 1.71 & 1.32 & 1.28 & 1.83 \\
\hline GFI & 0.84 & 0.53 & 0.51 & 0.49 & 0.50 & 0.49 & 0.53 & 0.75 & 0.68 & 0.49 \\
\hline RMSEA & 0.02 & 0.08 & 0.09 & 0.09 & 0.08 & 0.09 & 0.08 & 0.03 & 0.04 & 0.09 \\
\hline CFI & 0.98 & 0.80 & 0.75 & 0.75 & 0.79 & 0.75 & 0.79 & 0.96 & 0.95 & 0.75 \\
\hline ITG $\rightarrow$ BITA & $0.71^{\star * *}$ & $0.78^{* * *}$ & $0.73^{* * *}$ & $0.71^{\star * *}$ & $0.68^{\star * *}$ & $0.69^{* * *}$ & $0.69^{* * *}$ & $0.58^{\star * *}$ & $0.62^{* * *}$ & $0.59^{* * *}$ \\
\hline $\mathrm{R}^{2}-\mathrm{ITG}$ & 0.91 & 0.89 & 0.92 & 0.91 & 0.90 & 0.90 & 0.90 & 0.82 & 0.85 & 0.83 \\
\hline $\mathrm{R}^{2}$ - BITA & 0.96 & 0.94 & 0.96 & 0.96 & 0.95 & 0.95 & 0.95 & 0.94 & 0.94 & 0.94 \\
\hline
\end{tabular}

${ }_{* * *} \mathrm{p}<0.01$

Source: Own elaboration using AMOS estimates.

\section{CONCLUSIONS, LIMITATIONS, AND FURTHER RESEARCH}

Given the need to delve into the causal explanations in ITG studies (Tiwana et al. 2013), this research aimed to identify whether ITG had an impact on BITA following the suggestion of De Haes and Van Grembergem (2009). Furthermore, some authors consider BITA to be an important aspect of ITG (Tanriverdi 2006; Information Systems Audit and Control Association [ISACA] 2012; De Haes et al. 2013).

Several authors have studied certain relationships between the two main constructs of this study from different perspectives and found different results. Asante (2010) in an exploratory study identified a statistical correlation between some of the ITG structures proposed by Weill and Ross (2004) and strategic alignment. On the other hand, Gordon (2012) replicated Asante's (2010) study with a different sample using Luftman's model (2003) and adding the moderating effects of industry type and company size, without finding a relationship between ITG structures and BITA.

Meanwhile, Kuruzovich et al. (2012) found that the four ITG practices outlined by De Haes and Van Grembergem (2009) involving the board of directors affect BITA. Similarly, Hiekkanen (2016) used a mixed-method based on De Haes and Van Grembergem's (2009) model to measure ITG and Luftman's (2000) model to measure BITA, applied the above models qualitatively in a case study, and then conducted quantitative work with a sample of 42 surveys from 29 companies, finding a moderate positive relationship between ITG and BITA. Similarly, Lunardi et al. (2017) conclude that the adoption of structural, procedural, and relational mechanisms of ITG is positively associated with ITG domains, including strategic alignment. In contrast, Parry (2014) found no significant linear relationship between Weill and Ross's (2005) effective ITG and Tanriverdi's (2006) approach to BITA, based on a sample of 201 participants.
Unlike the studies mentioned above, this study used a method different from Luftman's (2000) to measure BITA in order to avoid endogeneity issues, as the latter looks at ITG as part of BITA. This research found that the mechanisms or practices of ITG (structures, processes, and relational mechanisms) have an impact on BITA, so a model was proposed to understand this impact. Due to the methodological application, results and the model evaluation show an adequate statistical adjustment of the proposed model, as well as the verification of the main hypothesis, which allows us to affirm that the model explains the relationship between ITG and BITA. About the moderating effect of the industry type and company size variables, it can be shown that it is not significant. From this finding, it is inferred that, although BITA is affected by ITG, there are no differences when it comes to firms of different sizes and sectors of activity.

The importance of jointly evaluating ITG mechanisms or practices is also noted, given their high correlation values and their contribution to the impact of ITG on BITA. The results described here have practical implications for enterprises, suggesting that the implementation of better ITG practices will generate better degrees of BITA and therefore improve organizational performance indicators. Instead, the non-implementation of such ITG practices may be one of the factors why BITA may not be developed. Having demonstrated ITG impact on BITA, one might think that BITA would act as a mediator of ITG impact on other constructs, for example, a firm's innovation capacity.

Future research should also include additional moderating or mediating effects, such as the type of ITG framework used by the company, the maturity of the company's IT department, whether multinational or not, and so on. Additional longitudinal research could also be conducted to analyze variation in ITG and BITA over time. 
Finally, it should be noted that this study is not without its limitations, which could be considered in future research. The data have been obtained in Colombia during a specific period, and it would be convenient to consider other countries, with larger samples of companies that include other industry types.

\section{ACKNOWLEDGMENTS}

This article is the result of research within the doctoral program of Strategic Business Administration of CENTRUM Católica, Pontificia Universidad Católica del Perú and the DBA program of Maastricht School of Management. The author expresses his special thanks to Professor Beatrice Avolio, Ph. D., for her special collaboration in advising on the development of the research.

\section{REFERENCES}

Aduloju, S.A., 2014. Information Technology Managerial Capabilities and Customer Service Performance Among Insurance Firms in Nigeria. SAGE Open, 4 (4), 1-11. DOI: 10.1177/2158244014561198

Alreemy, Z., Chang, V., Walters, R. and Wills, G., 2016. Critical success factors (CSFs) for information technology governance (ITG) International Journal of Information Management, 36 (6, Part A), 907-916. DOI: 10.1016/j.ijinfomgt.2016.05.017

Asante, K.K., 2010. Information Technology (IT) strategic alignment: A correlational study between the impact of IT governance structures and IT strategic alignment (Doctoral dissertation, Ph.D.). Capella University, Minneapolis, Minnesota.

Balocco, R., Ciappini, A. and Rangone, A., 2013. ICT Governance: A Reference Framework. Information Systems Management, 30 (2), 150-167. DOI: 10.1080/10580530.2013.773808

Bergeron, F., Croteau, A.-M., Uwizeyemungu and S., Raymond, L., 2015. IT Governance Framework Applied to SMEs. International Journal of IT/Business Alignment and Governance, 6 (1), 33-49. DOI: 10.4018/IJITBAG.2015010103

Bergeron, F., Raymond, L. and Rivard, S., 2004. Ideal patterns of strategic alignment and business performance. Information \& Management, 41 (8), 1003-1020. DOI: 10.1016/j.im.2003.10.004

Buchwald, A., Urbach, N. and Ahlemann, F., 2014. Business value through controlled IT: toward an integrated model of IT governance success and its impact. Journal of Information Technology, 29 (2), 128-147. DOI: $10.1057 /$ jit.2014.3

Byrne, B.M., 2010. Structural Equation Modeling with AMOS: Basic Concepts, Applications, and Programming. 2nd ed. New York, NY: Routledge.

Caluwe, L. and De Haes, S., 2019. Board Level IT Governance: A Scoping Review to Set the Research Agenda. Information Systems Management,36(3),262-283.DOI: 10.1080/10580530.2019.1620505

Cervone, H.F., 2017. Implementing IT governance: a primer for informaticians. Digital Library Perspectives, 33 (4), 282-287. DOI: 10.1108/DLP-07-2017-0023

Chan, Y.E. and Reich, B.H., 2007. IT alignment: what have we learned? Journal of Information Technology, 22 (4), 297-315. DOI: 10.1057/ palgrave.jit.2000109

Chan, Y.E., Sabherwal, R. and Thatcher, J.B., 2006. Antecedents and outcomes of strategic is alignment: An empirical investigation. IEEE Transactions on Engineering Management, 53 (1), 27-47. DOI: 10.1109/TEM.2005.861804
Charoensuk, S., Wongsurawat, W. and Khang, D.B., 2014. BusinessIT Alignment: A practical research approach. The Journal of High Technology Management Research, 25 (2), 132-147. DOI: 10.1016/j. hitech.2014.07.002

Chion, S. and Charles, V., 2016. Analítica de Datos para la Modelación Estructural. Lima, Perú: Pearson.

Coltman, T., Devinney, T.M., Midgley, D.F. and Venaik, S., 2008. Formative versus reflective measurement models: Two applications of formative measurement. Journal of Business Research, 61 (12), 12501262. DOI: $10.1016 /$ j.jbusres.2008.01.013

Coltman, T., Tallon, P., Sharma, R. and Queiroz, M., 2015. Strategic IT alignment: twenty-five years on. Journal of Information Technology, 30 (2), 91-100. DOI: 10.1057/jit.2014.35

Damanpour, F., 1991. Organizational Innovation: A Meta-Analysis of Effects of Determinants and Moderators. The Academy of Management Journal, 34 (3), 555-590.

De Haes, S., 2007. The impact of IT governance practices on business/ IT alignment in the Belgian financial services sector (Doctoral dissertation, Ph.D.). Universiteit Antwerpen, Belgium.

De Haes, S. and Van Grembergen, W., 2004. IT Governance and Its Mechanisms. Information Systems Control Journal, 1, 27-33.

De Haes, S. and Van Grembergen, W., 2008. Analysing the Relationship between IT Governance and Business/IT Alignment Maturity, in: 2008 41st Hawaii International Conference on System Sciences (HICSS), 428-437.

De Haes, S. and Van Grembergen, W., 2009. An Exploratory Study into IT Governance Implementations and its Impact on Business/ IT Alignment. Information Systems Management, 26 (2), 123-137. DOI: $10.1080 / 10580530902794786$

De Haes, S., Van Grembergen, W. and Debreceny, R.S., 2013. COBIT 5 and Enterprise Governance of Information Technology: Building Blocks and Research Opportunities. Journal of Information Systems, 27 (1), 307-324. DOI: 10.2308/isys-50422

Farooq, R., 2016. Role of structural equation modeling in scale development. Journal of Advances in Management Research, 13 (1), 75-91.

Gerow, J.E., Grover, V. and Thatcher, J., 2016. Alignment's nomological network: Theory and evaluation. Information \& Management, 53 (5), 541-553. DOI: 10.1016/j.im.2015.12.006

Gerow, J.E., Grover, V., Thatcher, J. and Roth, P.L., 2014. Looking Toward the Future of It-Business Strategic Alignment Through the Past: A Meta-Analysis. MIS Quarterly, 38 (4), 1159-1186.

Gerow, J.E., Thatcher, J.B. and Grover, V., 2015. Six types of IT-business strategic alignment: an investigation of the constructs and their measurement. European Journal of Information Systems, 24 (5), 465491. DOI: $10.1057 /$ ejis.2014.6

Gordon, F., 2012. Impact of Information Technology Governance Structures on Strategic Alignment (Doctoral dissertation, Ph.D.). Capella University, Minneapolis, Minnesota.

Gutiérrez, A., Orozco, J. and Serrano, A., 2009. Factors affecting IT and business alignment: a comparative study in SMEs and large organisations. Journal of Enterprise Information Management, 22 (1/2), 197-211. DOI: 10.1108/17410390910932830

Harguem, S., Karuranga, E. and Mellouli, S., 2014. Impact of IT Governance on Organizational Performance: Proposing an Explanatory Model, in: Proceedings of the European Conference on Management, Leadership \& Governance. 436-444.

Henderson, J.C. and Venkatraman, N., 1993. Strategic alignment: leveraging IT for transforming organizations. IBM Systems Journal, 32 (1), 472-484.

Héroux, S. and Fortin, A., 2018. The moderating role of IT-business alignment in the relationship between IT governance, IT competence, and innovation. Information Systems Management, 35 (2), 98-123. DOI: $10.1080 / 10580530.2018 .1440729$ 
Hiekkanen, K., 2016. Exploring the relationship between IT Governance and Strategic Alignment (Doctoral dissertation, Ph.D.). Aalto University, Helsinki.

Iacobucci, D., 2010. Structural equations modeling: Fit Indices, sample size, and advanced topics. Journal of Consumer Psychology, 20, 9098. DOI: $10.1016 /$ j.jcps.2009.09.003

Information Systems Audit and Control Association [ISACA], 2012. COBIT 5: A Business Framework for the Governance and Management of Enterprise IT. Rolling Meadows, IL: ISACA.

IT Governance Institute, 2003. Board briefing on IT governance. 2nd ed. Rolling Meadows, IL: IT Governance Institute.

Jia, Y., Wang, N. and Ge, S., 2018. Business-IT Alignment Literature Review: A Bibliometric Analysis. Information Resources Management Journal, 31 (3), 1-16. DOI: 10.4018/IRMJ.2018070103

Kaur, J., Mohamed, N. and Ahlan, Abd.R., 2011. A confirmatory factor analysis of the information technology governance effectiveness: Evidence from Malaysia. IEEE 2011 International Conference on Research and Innovation in Information Systems, Kuala Lumpur, 1-5. DOI: 10.1109/ICRIIS.2011.6125666

Kline, R., 2016. Principles and Practice of Structural Equation Modeling. 4th ed. New York: The Guilford Press.

Kude, T., Lazic, M., Heinzl, A. and Neff, A., 2018. Achieving IT-based synergies through regulation-oriented and consensus-oriented IT governance capabilities. Information Systems Journal, 28 (5), 765 795. DOI: $10.1111 /$ isj. 12159

Kuruzovich, J., Bassellier, G. and Sambamurthy, V., 2012. IT Governance Processes and IT Alignment: Viewpoints from the Board of Directors, in: 2012 45th Hawaii International Conference on System Sciences (HICSS), 5043-5052.

Levstek, A., Hovelja, T. and Pucihar, A., 2018. IT Governance Mechanisms and Contingency Factors: Towards an Adaptive IT Governance Model. Organizacija, 51 (4), 286-310. DOI: 10.2478/ orga-2018-0024

Luftman, J., 2000. Assessing Business-IT Alignment Maturity. Communications of the Association for Information Systems, 4 (14), 1-51.

Luftman, J., Dorociak, J., Kempaiah, R. and Rigoni, E.H., 2008. Strategic Alignment Maturity: A Structural Equation Model Validation. In: Proceedings of the Fourteenth Americas Conference on Information Systems, 53, 1-16.

Luftman, J., Zadeh, H.S., Derksen, B., Santana, M., Rigoni, E.H. and Huang, Z., 2013. Key information technology and management issues 20122013: an international study. Journal of Information Technology, 28 (4), 354-366. DOI: $10.1057 /$ jit.2013.22

Luftman, J.N., 2003. Competing in the Information Age. New York: Oxford University Press.

Lunardi, G.L., Gastaud Maçada, A.C., Becker, J. o L. and Van Grembergen, W., 2017. Antecedents of IT Governance Effectiveness: An Empirical Examination in Brazilian Firms. Journal of Information Systems, 31 (1), 41-57. DOI: 10.2308 /isys-51626

MacCallum, R., Browne, M. and Sugawara, H., 1996. Power analysis and determination of sample size for covariance structure modeling. Psychological Methods, 1 (2), 130-149.

Mardikyan, S., 2010. Analyzing the Usage of IT in SMEs. Communications of the IBIMA, 1-10. DOI: 10.5171/2010.208609

Olutoyin, O. and Flowerday, S., 2016. Successful IT governance in SMES: An application of the Technology-Organisation-Environment theory. South African Journal of Information Management, 18 (1), 1-8. DOI: $10.4102 /$ sajim.v18i1.696

Parry, V.A., 2014. The relationship between effective information technology governance and project portfolio control, risk management, and business/ information technology alignment in an organization (Doctoral dissertation, Ph.D.). Capella University, Minneapolis, Minnesota.
Peterson, R., 2004. Crafting Information Technology Governance. Information Systems Management, 21 (4), 7-22.

Ping-Ju Wu, S., Straub, D.W. and Liang, T.-P., 2015. How Information Technology Governance Mechanisms and Strategic Alignment Influence Organizational Performance: Insights from a Matched Survey of Business and IT Managers. MIS Quarterly, 39 (2), 497 A7.

Queiroz, M., 2017. Mixed results in strategic IT alignment research: a synthesis and empirical study. European Journal of Information Systems, 26 (1), 21-36. DOI: 10.1057/s41303-016-0024-z

Raymond, L., Bergeron, F., Croteau, A.-M. and Uwizeyemungu, S., 2019. Determinants and outcomes of IT governance in manufacturing SMEs: A strategic IT management perspective. International Journal of Accounting Information Systems, 35, 1-15. https://doi. org/10.1016/j.accinf.2019.07.001

Ruiz, M.A., Pardo, A. and Martín, R.S., 2010. Modelos De Ecuaciones Estructurales. Papeles del Psicólogo, 31 (1), 34-45.

Sabherwal, R., Hirschheim, R. and Goles, T., 2001. The Dynamics of Alignment: Insights from a Punctuated Equilibrium Model. Organization Science, 12 (2), 179-197.

Saunders, M.N.K., Lewis, P. and Thornhill, A., 2019. Research Methods for Business Students. 8th ed. Harlow: Pearson Education, Limited.

Schreiber, J.B., Nora, A., Stage, F.K., Barlow, E.A. and King, J., 2006. Reporting Structural Equation Modeling and Confirmatory Factor Analysis Results: A Review. Journal of Educational Research, 99 (6), 323-337. DOI: 103200/JOER.99.6.323-338

Shihab, M.R., Rahardian, I., 2017. Comparing the approaches of small, medium, and large organisations in achieving IT and business alignment. International Journal of Business Information Systems, 24 (2), 227-241.

Tallon, P.P. and Pinsonneault, A., 2011. Competing Perspectives on the Link Between Strategic Information Technology Alignment and Organizational Agility: Insights from a Mediation Model. MIS Quarterly, 35 (2), 463-486.

Tanriverdi, H., 2006. Performance Effects of Information Technology Synergies in Multibusiness Firms. MIS Quarterly, 30, 57-77.

Tanriverdi, H., Rai, A. and Venkatraman, N., 2010. Reframing the Dominant Quests of Information Systems Strategy Research for Complex Adaptive Business Systems. Information Systems Research, 21 (1), 822-834. DOI: 10.1287/isre.1100.0317

Tiwana, A., Konsynski, B. and Venkatraman, N., 2013. Special Issue: Information Technology and Organizational Governance: The IT Governance Cube. Journal of Management Information Systems, 30 (3), 7-12. DOI: $10.2753 /$ MIS0742-1222300301

Van Grembergen, W., 2004. Strategies for Information Technology Governance. Hershey, PA: Idea Group Inc (IGI).

Van Grembergen, W. and De Haes, S., 2008. Implementing Information Technology Governance: Models, Practices and Cases: Models, Practices and Cases. Hershey, PA: IGI Global.

Van Grembergen, W., De Haes, S. and Guldentops, E., 2004. Structures, Processes and Relational Mechanisms for IT Governance, in: Strategies for Information Technology Governance. Hershey, PA: Idea Group Publishing, 1-35.

Venkatraman, N., 1989. Strategic Orientation of Business Enterprises: The Construct, Dimensionality, and Measurement. Management Science, 35 (8), 942-962.

Wagner, H.-T., Beimborn, D. and Weitzel, T., 2014. How social capital among information technology and business units drives operational alignment and it business value. Journal of Management Information Systems, 31 (1), 241-272. DOI: 10.2753/MIS0742-1222310110

Weill, P. and Ross, J., 2005. A Matrixed Approach to Designing IT Governance. MIT Sloan Management Review, 46 (2), 26-34. 
Weill, P. and Ross, J., 2004. IT Governance: How Top Performers Manage IT Decision Rights for Superior Results. Boston, MA: Harvard Business Review Press.

Weill, P., Subramani, M. and Broadbent, M., 2002. Building IT Infrastructure for Strategic Agility. MIT Sloan Management Review, 44 (1), 57-65.

Wolf, E.J., Harrington, K.M., Clark, S.L. and Miller, M.W., 2013. Sample Size Requirements for Structural Equation Models: An Evaluation of Power, Bias, and Solution Propriety. Educational and psychological measurement, 76 (6), 913-934. DOI: $10.1177 / 0013164413495237$
Yayla, A.A. and Hu, Q., 2012. The impact of IT-business strategic alignment on firm performance in a developing country setting: exploring moderating roles of environmental uncertainty and strategic orientation. European Journal of Information Systems, 21 (4), 373-387. DOI: $10.1057 /$ ejis.2011.52

Zhang, M., Chen, H. and Luo, A., 2018. A Systematic Review of BusinessIT Alignment Research With Enterprise Architecture. IEEE Access, 6, 18933-18944. DOI: 10.1109/ACCESS.2018.2819185

Zhang, P., Zhao, K. and Kumar, R.L., 2016. Impact of IT Governance and IT Capability on Firm Performance. Information Systems Management,33(4),357-373.DOI:10.1080/10580530.2016.1220218. 